Masuma H. Mammadova, Zarifa G. Jabrayilova

Institute of Information Technology of ANAS, Baku, Azerbaijan

depart15@ iit.ab.az

\title{
METHODS MANAGING FOR AGREED SUPPLY AND DEMAND ON THE MEDICAL SPECIALISTS
}

The article presents fuzzy situational model of supply and demand for medical specialists, and proposes the methods based on fuzzy similarity of the situation for the intelligent management of supply and demand. The technique for the decision-making on the recruitment of medical specialists is developed in accordance with possible scenarios in hospitals. The article sheds a light on the algorithm and implementation phases of the issue resolution

Keywords: health professionals, demand model, supply model, fuzzy similarity situation, fuzzy equality situation, relative importance ratio.

\section{Introduction}

Provision of human resources and the professional level of the medical employees are the most essential and vital factors directly affecting the quality of the medical services delivered to the population. Thus, improvement of the health workforce and developing the professional level of the medical employees are the priorities of each country and the World Health Organization (WHO) as a whole [1-3]. The program "Assessing future health workforce needs" adopted by World Health Organization and European Observatory on Health Systems and Policies of the World Health Organization defines the balancing supply and demand for the health workforce as a global problem [3]. The relevance of this problem is proven by the policy of the European Union and Green paper on the European workforce for health introduced in 2008 [4]. Successful resolution of the pending issue requires the development of a comprehensive strategy covering issues such as an ample approach to the problem, staff wages, working conditions, recruitment and motivation. However, a standard model in this area is not available yet, and there is no a country with the good practices which would be conducive to solving this issue. Nevertheless, at present, sufficient attention is not paid on the solution of the problem in the scientific literature [3].

This paper proposes a methodological approach for the management of the demand and supply in the market of health workforce, and provides methods for the solution of intelligent management of the demand and supply in the medical institutions based on fuzzy situation analysis and similarity. Whilst mentioning the intelligent management of the health workforce market, the authors consider such management solutions selected among the possible alternative options of compliance policy of supply and demand in order to reduce the imbalance of between the supply and demand to the health professionals. This decision would fully comply with the aims and conditions of the problem, to the requirements, interests and terms of the main subjects of the labor market, which are employers and medical experts, at the possible extent, and would minimize the deviation between the supply and demand [5].

\section{Compliance of demand and supply of health specialists}

People, their intellectual potential, personal and psychological qualities are the main resources of the health workforce market [6]. The specificity of the health workforce market, the uncertainty of the data sets about its situation, the diverse nature of the data about the health workforce and in most cases, the impossibility of their measurement define the diversity of fuzzy situations of supply and demand to health professionals and the multi-variation of their possible balancing. Making decisions on the solution of comparison and assessment issues of these situations and selection of their relevance policy may be effective through the use of intellectual methods and technology. These tools may form a set of alternative options of management decisions related to the supply and demand situations. In such systems, the management is considered as a process of identification of the situation of supply/demand at a certain moment and 
management decision-making adequate to the current situation. Taking into account the fact that the structure and volume of the demand for health professionals, the requirements to their professional and personal competencies are established at health institutions, the study case reviews the compliance issue of demand and supply at the level of health institutions to adapt to the level of popular are considered in the article. In this regard, the solution of the issue of the compliance of supply and demand is reduced to the development of mechanisms for the selection and recruitment of health specialists. Successful implementation of the professional duties by the health workforce depends on their intellectual potential, a certain degree of mastering the professional and personal competencies, readiness to use them in particular workplace, and their desire and ability to regularly improve and update the knowledge and skills in the professional area. In this context, the labor market should be considered as an intellectual environment, which yields knowledge, skills and abilities [7, 8].

\subsection{Fuzzy situation models of supply and demand for health specialists}

Assume the demand for health specialists labor market is defined by the following sets: $V=\left\{V_{1}, V_{2}, \ldots, V_{k}\right\}$ or $V=\left\{V_{i}\right\}, i=\overline{1, k}$ expresses a set of vacancies;

$L=\left\{l_{1}, l_{2}, \ldots, l_{n}\right\}$ or $L=\left\{l_{i}\right\}, j=\overline{1, n}$ is a set of personal features (characteristics) required in a candidate to a particular position (position, workplace); $C=\left\{c_{1}, c_{2}, \ldots, c_{m}\right\}$ or $C=\left\{c_{f}\right\}, f=\overline{1, m}$ is an open set of competencies sought to fill the medical vacancy; $U=\left\{u_{1}, u_{2}, \ldots, u_{p}\right\}$ or $U=\left\{u_{\gamma}\right\}, \gamma=\overline{1, p}$ is a set of terms offered to the applicants to vacant medical jobs.

The demand model $V=(L, C, U)$ can be described by three matrices as $V_{L}=\left\|l_{i j}\right\|_{k n}$, $V_{C}=\left\|c_{i f}\right\|_{k m}$ and $V_{U}=\left\|u_{i \gamma}\right\|_{k p}$, where every $i=\overline{1, k}$ of the row $V_{i}$ characterizes individual vacancies in the medical labor market; the columns $\left(l_{k n}, c_{k m}, u_{k p}\right)$ represent the constantly expanding base of personality features and competencies; the elements $l_{k n}, c_{k m}$ express the level of individual characteristics require to fill the vacancy, and $u_{q p}$ are the values of measures characterizing the conditions proposed to applicants for a particular vacancy. The degree of conformity of the vacancy $V_{i}(i=\overline{1, k})$ by the indicators $l_{i j}, c_{i f}$ and $u_{k p}$ is defined as fuzzy sets with membership functions

$$
\mu_{l_{i j}}\left(V_{i}\right): V \times L \rightarrow[0,1], \mu_{c_{i f}}\left(V_{i}\right): V \times C \rightarrow[0,1], \mu_{u_{i \gamma}}\left(V_{i}\right): V \times U \rightarrow[0,1]
$$

expressing the levels of membership required by the employment on separate indicators to fill the vacancy.

Assuming that the health specialists seeking and applying for a vacancy in the labor market is given as a set $S=\left\{S_{1}, S_{2}, \ldots, S_{q}\right\}$ or $S=\left\{S_{g}\right\}, g=\overline{1, q} \cdot L=\left\{l_{i}\right\}, j=\overline{1, n}$ is a set of actual competencies characterizing the health specialists, $C=\left\{c_{f}\right\}, f=\overline{1, m}$ is a set of actual competencies in each individual applicant to a vacancy, $U=\left\{u_{\gamma}\right\}, \gamma=\overline{1, p}$ is a set of preferences of the medical specialist expressed in the requirements of the medical expert for the medical vacancy.

The supply model $S=(L, C, U)$ is also given as three matrices $S_{L}=\left\|l_{g j}\right\|_{q n}, S_{C}=\left\|c_{g f}\right\|_{q m}$, and $S_{U}=\left\|u_{g \gamma}\right\|_{q p}$, in which each row of $\left(S_{g}\right)(g=\overline{1, q})$ characterizes individual candidates to proposed vacancies in the medical job market; the columns $\left(l_{n}, c_{m}, u_{p}\right)$ reflect the constantly expanding base of personal features and competencies; the elements $l_{q n}, c_{q m}$ are the levels of individual attributes required to fill the vacancy; and $u_{q p}$ is a set of the indicators describing the 
requirements of the medical specialist for the vacancy. The degree of a competency of a certain medical specialist $S_{g}$ with the individual features $g=\overline{1, q} L$, competency $C$, and the vacancy requirements $U$ is defined by the following membership function:

$$
\mu_{l_{g j}}\left(S_{g}\right): S \times L \rightarrow[0,1], \quad \mu_{c_{g f}}\left(S_{g}\right): S \times C \rightarrow[0,1], \quad \mu_{u_{g \gamma}}\left(S_{g}\right): S \times U \rightarrow[0,1] .
$$

In fact, there are two sets of fuzzy situations describing the conditions of demand $\tilde{V}_{i}$ and supply $\tilde{S}_{g}$ in the health specialist labor market:

$$
\begin{gathered}
\tilde{V}_{i}=\left\{<\mu_{l_{i j}}\left(V_{i}\right)>,<\mu_{c_{i f}}\left(V_{i}\right)>,<\mu_{u_{i \gamma}}\left(V_{i}\right)>\right\}=\left\{\mu_{V_{i}}(y) / y\right\} \\
\tilde{S}_{g}=\left\{<\mu_{l_{g j}}\left(S_{g}\right)>,<\mu_{c_{g f}}\left(S_{g}\right)>,<\mu_{u_{g \gamma}}\left(S_{g}\right)>\right\}=\left\{\mu_{S_{g}}(y) / y\right\} .
\end{gathered}
$$

Here, the set $\tilde{V}_{i}=\left\{\mu_{V_{i}}(y) / y\right\}, i=\overline{1, k}$ accounts for fuzzy referencesituations, i.e., sought fuzzy images of demand. Moreover, the set $\tilde{S}_{g}=\left\{\mu_{S_{g}}(y) / y\right\} g=\overline{1, q}$ accounts for fuzzy real situations, i.e. sought fuzzy images of supply. Thus, the purpose of the task is to identify the similarity of supply fuzzy situation images with the demand fuzzy reference situation image for the intellectual management of the compliance of supply and demand in the health workforce market and to define the pair with a greater similarity (proximity) rate.

\subsection{The methods for the recognition of fuzzy supply and demand images for health specialists}

Thus, the statement and objective of the decision task related to the compliance of supply and demand are based on the management of situations using the determination of the proximity measure and similarity rate between the two fuzzy situations. As the measure of identifying the proximity rate of fuzzy real and reference situations the determination of the fuzzy inclusion of situation $\tilde{S}_{g}$ in fuzzy situation $\tilde{V}_{i}$ can be used; and the determination of the degrees of fuzzy equality of $\tilde{S}_{g}$ and $\tilde{V}_{i}$ can be used [8-10]:

1. The fuzzy inclusion $\theta\left(\tilde{S}_{g}, \tilde{V}_{i}\right)$ of situation $\tilde{S}_{g}$ in fuzzy situation $\tilde{V}_{i}$ is defined as follows:

$$
\theta\left(\tilde{S}_{g}, \tilde{V}_{i}\right)=\& \theta\left(\mu_{S_{g}}(y), \mu_{V_{i}}(y)\right)=\underset{y \in Y}{\&}\left(\max \left(1-\mu_{S_{g}}(y), \mu_{V_{i}}(y)\right)\right)=\min \left(\max \left(1-\mu_{S_{g}}(y), \mu_{V_{i}}(y)\right)\right)(5)
$$

If the inclusion degree of situation $\tilde{S}_{g}$ in situation $\tilde{V}_{i}$ is not less than the fuzzy inclusion limit $\psi$, which is adopted in accordance with the management condition (for example, $\psi \in[0,6 ; 1])$, that is, $\theta\left(\tilde{S}_{g}, \tilde{V}_{i}\right) \geq \psi$, then the situation $\tilde{S}_{g}$ is fuzzy included into the situation $\tilde{V}_{i}$, that is $\left(\tilde{S}_{g} \subseteq \tilde{V}_{i}\right)$. In other words, if the fuzzy value of the indices of the situation $\tilde{S}_{g}$ (the real values of the indices characterizing a candidate for the vacancy) is fuzzy included into the values of the indices of the situation $\tilde{V}_{i}$ (the reference values of the indices required from the applicant), then the situation $\tilde{S}_{g}$ is fuzzy included into the situation $\tilde{V}_{i}$.

To make decision, each alternative situation out of the sets of candidates applying to the vacancy (situations of the sets of vacancies) is compared to the degree of inclusion into the reference images, and the candidate with the highest value is selected based on the following statement:

$$
\max \left[\min \left(\max \left(1-\left(\mu_{S_{g}}(y), \mu_{V_{i}}(y)\right)\right)\right], g=\overline{1, q}, i=\overline{1, k} .\right.
$$

2. Fuzzy equality (equivalence) rate AS the measure of the similarity rate of random fuzzy situation is determined as follows. Assume that, $\psi$ is adopted as a fuzzy equality rate of the two 
situations (for example, $\psi \in[0,7 ; 1]$ ), and if there are the situations included into one another, i.e., $\tilde{S}_{g} \subseteq \tilde{V}_{i}$ and $\tilde{V}_{i} \subseteq \tilde{S}_{g}, g=\overline{1, q}, i=\overline{1, k}, g \neq k$, then situations $\tilde{S}_{g}$ and $\tilde{V}_{i}$ are considered to be approximately equal. Such similarity rate so-called fuzzy equality situations is calculated according to the following statement:

$$
\begin{aligned}
& \mu\left(\tilde{S}_{g}, \tilde{V}_{i}\right)=\vee\left(\tilde{S}_{g}, \tilde{V}_{i}\right) \vee\left(\tilde{V}_{i}, \tilde{S}_{g}\right)=\& \mu\left(\mu_{S_{g}}(y), \mu_{V_{i}}(y)\right)= \\
& =\min _{y \in Y}\left[\min \left(\max \left(1-\mu_{S_{g}}(y), \mu_{V_{i}}(y)\right), \max \left(\mu_{S_{g}}(y), 1-\mu_{V_{i}}(y)\right)\right)\right] .
\end{aligned}
$$

when $\psi \in[0,7 ; 1]$, if $\mu\left(\tilde{S}_{g}, \tilde{V}_{i}\right) \geq \psi$, the situations $\tilde{S}_{g}$ and $\tilde{V}_{i}$ are considered to be equally fuzzy, that is $\tilde{S}_{g} \approx \tilde{V}_{i}$.

\section{Management methods on possible scenarios of the compliance of demand and supply for health specialists}

Several possible scenarios can be available for the identification of the most acceptable pairs for "employer-medical specialist" by their proximity rate out of the sets of the real images of the health specialists and survey's reference images[5]:

Scenario 1.One vacancy (employer's request) - one applicant (health specialist).

In this case, if the degree of fuzzy similarity (reference search image of the vacancy and real image of the applicant) of the two situations is not less than the limit accepted by the employer, then a hiring decision is made.

Scenario 2. Several applicants (health specialists) respond to the employer's attitude in accordance with the accepted similarity measure of the two fuzzy situations. The latter ones create the subsets of fuzzy situations (alternatives), out of which most eligible one should be selected.

In this case, the employer is offered the following decision methods:

2.1. The proximity rates of reference and real situations are compared by the criteria describing the candidates for the vacancy and the decision on the most consistent situations is made.

2.2. The task of decision making is reduced to the multi-criteria selection of better alternative, taking into account the relative importance criteria characterizing the applicants for the vacancy[11].

In this case, the decision is made in the following stages:

Stage 1.The situations that do not provide fuzzy inclusion or equality limit are "filtered", i.e., certain offer images do not participate in the next stages.

Stage 2. The relative importance ratios of the criteria and indicators are set [12,13]. For this purpose, comparison matrix is established according to the diagonal, symmetry and transitiveness characteristics of the Saati schedule and matrix. Using one of the four approaches proposed in [12, 13], the relative importance ratios are calculated.

In order to check whether there is any controversies within the statements of the employer and to detect the controversies, the maximum intrinsic value of the matrix $-\lambda_{\max }$, Consistency Index $(\mathrm{CI})$ and Consistency Ratio (CR) are calculated. For this purpose, based on the method of multiplication of matrix by the vectors, a rough estimation method of consistency is referenced [12]. Multiplying the comparison matrix by the obtained decision vector (relative importance ratios), a new vector is obtained, and another vector is obtained by dividing its first component by the first component of the decision vector, its second component by the second component of the decision vector and so forth. $\lambda_{\max }$ (maximum or head special intrinsic value) is obtained by dividing the sum of this vector components by the number of components. The closer the value of $\lambda_{\max }$ to $n$, the more the result is considered to be agreed. The deviation from the consistency is called consistency index $(\mathrm{CI})$ and this limit is determined by the following formula:

$$
C I=\left(\lambda_{\max }-n\right) /(n-1)
$$


Dividing the matrix consistency index by the Random consistency (RC) limit defines the consistency relation $(\mathrm{CR})$ :

$$
C R=C I / R C \text {. }
$$

According to [12], random consistency $\mathrm{RC}=0,58$ for $n=3$ dimensional matrix; $R C=0,90$ for $n=4 ; R C=1,12$ for $\mathrm{n}=54 ; \mathrm{RC}=1,24$ for $n=6$ and so forth.

If $C R \leq 0,1$, consistency limit is considered to be acceptable, otherwise expert values are required to be revised.

Step 3. The fuzzy similarity rate of the fuzzy real situations with the reference situations is defined based on indicators aggregation $[11,14]$. This is performed by the following steps.

3.1.Establishing" convolution " of the indicators $l_{1}, l_{2}, \ldots, l_{n}, S=\left\{S_{g}\right\}, g=\overline{1, q}$, the fuzzy similarity degree of fuzzy real situations with the fuzzy reference situations $V=\left\{V_{i}\right\}, i=\overline{1, k}$ according to L is set:

$$
\mu_{L}\left(S_{g}\right)=\sum_{j=1}^{n} w_{j} \mu_{l_{j}}\left(S_{g}\right) .
$$

3.2.Establishing" convolution " of the indicators $c_{1}, c_{2}, \ldots, c_{m}, S=\left\{S_{g}\right\}, g=\overline{1, q}$, the fuzzy similarity degree of fuzzy real situations with the fuzzy reference situations $V=\left\{V_{i}\right\}, i=\overline{1, k}$ according to $\mathrm{C}$ is set:

$$
\mu_{C}\left(S_{g}\right)=\sum_{f=1}^{m} w_{f} \mu_{c_{f}}\left(S_{g}\right) .
$$

3.3. Establishing" convolution " of the indicators $u_{1}, u_{2}, \ldots, u_{p}, S=\left\{S_{g}\right\}, g=\overline{1, q}$, the fuzzy similarity degree of fuzzy real situations with the fuzzy reference situations $V=\left\{V_{i}\right\}, i=\overline{1, k}$ according to $\mathrm{U}$ is set:

$$
\mu_{U}\left(S_{g}\right)=\sum_{\gamma=1}^{p} w_{\gamma} \mu_{u_{\gamma}}\left(S_{g}\right) .
$$

3.4. Based on the obtained results and relative importance ratios $w_{L}, w_{C}, w_{U}$ of the criteria $\mathrm{L}$, $\mathrm{C}, \mathrm{U}$, the similarity degree of the fuzzy real situations to the reference situations is determined:

$$
\mu_{V}\left(S_{g}\right)=\omega_{L} \cdot \mu_{L}\left(S_{g}\right)+\omega_{C} \cdot \mu_{C}\left(S_{g}\right)+\omega_{U} \cdot \mu_{U}\left(S_{g}\right)
$$

3.5. The fuzzy real situation with the highest value is selected:

$$
\mu(S *)=\max \left\{\mu_{K}\left(S_{i}\right), i=\overline{1, n}\right\} .
$$

The selected fuzzy real situation is the image of the sought applicant with the highest degree of similarity to the reference vacancy image, and that can be regarded as the best decision.

\section{Implementation of the management methods of supply and demand for health professionals}

Assuming there are two vacancies $V=\left\{V_{1}, V_{2}\right\}: V_{1}$ - a pediatrician for private city clinic and $\mathrm{V}_{2}$ - a pediatrician for the district hospital and 4 candidates applying to these vacancies $S=\left\{S_{1}, S_{2}, S_{3}, S_{4}\right\}$. Solution stages of the recruitment of the 4 applicants to 2 vacancies are given below using the fuzzy equality method for the determination of the similarity degree of the fuzzy situations (note that, in the given issue, the vacancy is referred as the reference situation, and therefore, the similarity degrees obtained with the application of fuzzy inclusion of the situations and fuzzy equality methods provide the same result).

1st stage. Reference situation model of vacancies is established, that is, the system of indicators characterizing it is formed. Note that the data on the recruitment of health professionals obtained from the sites [15-18] is used for the formation of the indicators system of the vacancies $V_{1}$ and $V_{2}$ (Table 1). 
Indicators system of the vacancies $V_{1}$ and $V_{2}$

\begin{tabular}{|c|c|c|c|}
\hline \multirow{2}{*}{ Vacancies } & \multirow{2}{*}{ Criteria } & \multicolumn{2}{|r|}{ Indicators } \\
\hline & & $\begin{array}{l}\text { Conventional } \\
\text { signs }\end{array}$ & linguistic variables \\
\hline \multirow{10}{*}{$V_{1}$} & \multirow{3}{*}{$\begin{array}{c}\text { Personal Qualities } \\
\qquad L\end{array}$} & $l_{1}$ & sociable, friendly \\
\hline & & $l_{2}$ & Responsible \\
\hline & & $l_{3}$ & self developing \\
\hline & \multirow{4}{*}{$\begin{array}{c}\text { Competence, } \\
\text { knowledge and skills } \\
\text { C }\end{array}$} & $c_{1}$ & $\begin{array}{l}\text { level of knowledge in accordance with the } \\
\text { university diploma in "pediatrics" }\end{array}$ \\
\hline & & $c_{2}$ & assured computer skills \\
\hline & & $c_{3}$ & perfect knowledge of vocational skills \\
\hline & & $c_{4}$ & presentation of competent writing skills \\
\hline & \multirow{3}{*}{$\begin{array}{l}\text { Vacancy terms and } \\
\text { requirements } \\
U\end{array}$} & $u_{1}$ & at least 3 years practical experience \\
\hline & & $u_{2}$ & re-qualification certificate \\
\hline & & $u_{3}$ & Fluent Azerbaijani and Russian \\
\hline \multirow{7}{*}{$V_{2}$} & \multirow{2}{*}{$\begin{array}{l}\text { Personal Qualities } \\
\qquad L\end{array}$} & $l_{l}$ & responsible, considerate \\
\hline & & $l_{2}$ & Adaptive \\
\hline & \multirow{2}{*}{$\begin{array}{c}\text { Competence, } \\
\text { knowledge and skills } \\
\text { C }\end{array}$} & $c_{1}$ & $\begin{array}{l}\text { level of knowledge in accordance with } \\
\text { the university diploma in "pediatrics" }\end{array}$ \\
\hline & & $c_{2}$ & perfect knowledge of vocational skills \\
\hline & \multirow{3}{*}{$\begin{array}{l}\text { Vacancy terms and } \\
\text { requirements } \\
U\end{array}$} & $u_{1}$ & living and working in villages and districts \\
\hline & & $u_{2}$ & intense work schedule \\
\hline & & $u_{3}$ & Fluent Azerbaijani $\left(u_{3}\right)$ \\
\hline
\end{tabular}

2nd stage. To define the level of compliance of the applicants with the parameters that characterize the vacancy, the mathematical formalization of the indicators is set. For this purpose, the linguistic variables measured by verbal rating scale and grades are referred to. In this case, the levels of the linguistic variable, that is gradations vary according to the increase in the intensity of self-expression of the indicators. In our case, the gradations of the linguistic variables equal to 5 (e.g., excellent, good, normal, satisfactory, poor). Table 2shows 5-point scale of the index "sociable and friendly" and respective fuzzy values set defined in the interval $[0 ; 1][7,19,20]$.

Table 2.

"Sociable and friendly" index fuzzyfication

\begin{tabular}{|l|c|c|}
\hline "Sociable and friendly" index gradations & Linguistic value & Fuzzy set in the interval $[0,1]$ \\
\hline 1) very sociable and friendly & excellent & {$[0,95-1]$} \\
\hline 2) sociable and friendly & good & {$[0,8-0,94]$} \\
\hline 3) sociable & normal & {$[0,5-0,79]$} \\
\hline 4) almost sociable & satisfactory & {$[0,26-0,49]$} \\
\hline 5) quiet and unsociable & poor & {$[0,1-0,25]$} \\
\hline
\end{tabular}

3rd stage. Assuming the compliance of the applicants $S=\left\{S_{1}, S_{2}, S_{3}, S_{4}\right\}$ to the vacancy $\mathrm{V}_{1}$ with the indicators characterizing this vacancy is assessed by the employer (expert) as below (Table 3 ). 
Table 3.

Expert assessments of the applicants $S=\left\{S_{1}, S_{2}, S_{3}, S_{4}\right\}$ to the vacancy $\mathrm{V}_{1}$

\begin{tabular}{|c|c|c|c|c|}
\hline $\begin{array}{l}\text { Applicants to the vacancy } \mathrm{V}_{1} \\
\text { Indicators } \\
\text { characterizing the vacancy } V_{1}\end{array}$ & $S_{1}$ & $S_{2}$ & $S_{3}$ & $S_{4}$ \\
\hline \multicolumn{5}{|l|}{ Personal qualities $(L)$} \\
\hline sociable, friendly $\left(l_{1}\right)$ & excellent & good & good & Normal \\
\hline responsible $\left(l_{2}\right)$ & good & good & Good & Good \\
\hline self-developing $\left(l_{3}\right)$ & good & good & Normal & Good \\
\hline \multicolumn{5}{|l|}{ Competence, knowledge and skills $(C)$} \\
\hline $\begin{array}{l}\text { level of knowledge in accordance with the } \\
\text { university diploma in "pediatrics" }\left(c_{1}\right)\end{array}$ & excellent & excellent & Good & excellent \\
\hline assured computer skills $\left(c_{2}\right)$ & Good & Good & normal & good \\
\hline perfect knowledge of vocational skills $\left(c_{3}\right)$ & excellent & excellent & Good & good \\
\hline presentation of competent writing skills $\left(c_{4}\right)$ & Good & excellent & Good & normal \\
\hline \multicolumn{5}{|l|}{ Terms and requirements $(U)$} \\
\hline at least 3 years practical experience $\left(u_{1}\right)$ & Good & good & excellent & excellent \\
\hline re-qualification certificate $\left(u_{2}\right)$ & Good & good & excellent & excellent \\
\hline Fluent Azerbaijani and Russian $\left(u_{3}\right)$ & excellent & excellent & Good & good \\
\hline
\end{tabular}

The compliance of the applicants with the indicators characterizing the vacancy $\mathrm{V}_{1}$ is given in Table 4.

Table 4.

The compliance of the applicants with the indicators characterizing the vacancy $\mathrm{V}_{1}$

\begin{tabular}{|c|c|c|c|c|}
\hline $\begin{array}{l}\text { Indicators } \\
\text { characterizing } \\
\text { the vacancy } V_{l}\end{array}$ & $\begin{array}{c}S_{1} \\
\mu_{L_{j}}\left(S_{1}\right) \rightarrow[0,1], j=\overline{1,3} \\
\mu_{C_{f}}\left(S_{1}\right) \rightarrow[0,1], f=\overline{1,4} \\
\mu_{U_{\gamma}}\left(S_{1}\right) \rightarrow[0,1], \gamma=\overline{1,3}\end{array}$ & $\begin{array}{c}S_{2} \\
\mu_{L_{j}}\left(S_{2}\right) \rightarrow[0,1], j=\overline{1,3} \\
\mu_{C_{f}}\left(S_{2}\right) \rightarrow[0,1], f=\overline{1,4} \\
\mu_{U_{y}}\left(S_{2}\right) \rightarrow[0,1], \gamma=\overline{1,3}\end{array}$ & $\begin{array}{c}S_{3} \\
\mu_{L_{j}}\left(S_{3}\right) \rightarrow[0,1], j=\overline{1,3}, \\
\mu_{C_{f}}\left(S_{3}\right) \rightarrow[0,1], f=\overline{1,4} \\
\mu_{U_{\gamma}}\left(S_{3}\right) \rightarrow[0,1], \gamma=\overline{1,3}\end{array}$ & $\begin{array}{c}S_{4} \\
\mu_{L_{j}}\left(S_{4}\right) \rightarrow[0,1], j=\overline{1,3} \\
\mu_{C_{f}}\left(S_{4}\right) \rightarrow[0,1], f=\overline{1,4} \\
\mu_{U_{\gamma}}\left(S_{4}\right) \rightarrow[0,1], \gamma=\overline{1,3}\end{array}$ \\
\hline \multicolumn{5}{|l|}{ Personal qualities $(L)$} \\
\hline sociable, friendly $\left(l_{1}\right)$ & 0,97 & 0,88 & 0,82 & 0,65 \\
\hline responsible $\left(l_{2}\right)$ & 0,89 & 0,85 & 0,89 & 0,82 \\
\hline self-developing $\left(l_{3}\right)$ & 0,87 & 0,8 & 0,70 & 0,9 \\
\hline \multicolumn{5}{|l|}{$\begin{array}{l}\text { Competence, knowledge and } \\
\text { skills }(C)\end{array}$} \\
\hline $\begin{array}{l}\text { level of knowledge in } \\
\text { accordance with the university } \\
\text { diploma in "pediatrics" }\left(c_{1}\right)\end{array}$ & 0,98 & 0,95 & 0,82 & 0,97 \\
\hline assured computer skills $\left(c_{2}\right)$ & 0,9 & 0,84 & 0,75 & 0,88 \\
\hline $\begin{array}{l}\text { perfect knowledge of } \\
\text { vocational skills }\left(c_{3}\right)\end{array}$ & 0,95 & 0,97 & 0,80 & 0,82 \\
\hline $\begin{array}{l}\text { presentation of competent } \\
\text { writing skills }\left(c_{4}\right)\end{array}$ & 0,82 & 0,95 & 0,9 & 0,70 \\
\hline \multicolumn{5}{|l|}{ Terms and requirements $(U)$} \\
\hline $\begin{array}{l}\text { at least } 3 \text { years practical } \\
\text { experience }\left(u_{1}\right)\end{array}$ & 0,90 & 0,94 & 0,97 & 0,96 \\
\hline re-qualification certificate $\left(u_{2}\right)$ & 0,82 & 0,82 & 0,97 & 0,95 \\
\hline $\begin{array}{l}\text { Fluent Azerbaijani and } \\
\text { Russian }\left(u_{3}\right)\end{array}$ & 0,95 & 0,95 & 0,8 & 0,88 \\
\hline
\end{tabular}


According to Table 4.fuzzy real situations, i.e.fuzzy images of the applicants to the vacancy $\mathrm{V}_{1}$ are formed:

$$
\begin{aligned}
& \tilde{S}_{1}=\left\{0,97 / l_{1} ; 0,89 / l_{2} ; 0,87 / l_{3} ; 0,98 / c_{1} ; 0,9 / c_{2} ; 0,95 / c_{3} ; 0,82 / c_{4} ; 0,9 / u_{1} ; 0,82 / u_{2} ; 0,95 / u_{3}\right\} \\
& \tilde{S}_{2}=\left\{0,88 / l_{1} ; 0,85 / l_{2} ; 0,8 / l_{3} ; 0,95 / c_{1} ; 0,84 / c_{2} ; 0,97 / c_{3} ; 0,95 / c_{4} ; 0,94 / u_{1} ; 0,82 / u_{2} ; 0,95 / u_{3}\right\} \\
& \tilde{S}_{3}=\left\{0,82 / l_{1} ; 0,89 / l_{2} ; 0,70 / l_{3} ; 0,82 / c_{1} ; 0,75 / c_{2} ; 0,8 / c_{3} ; 0,9 / c_{4} ; 0,97 / u_{1} ; 0,97 / u_{2} ; 0,8 / u_{3}\right\} \\
& \tilde{S}_{4}=\left\{0,65 / l_{1} ; 0,82 / l_{2} ; 0,9 / l_{3} ; 0,97 / c_{1} ; 0,88 / c_{2} ; 0,82 / c_{3} ; 0,7 / c_{4} ; 0,96 / u_{1} ; 0,95 / u_{2} ; 0,88 / u_{3}\right\}
\end{aligned}
$$

Where as, the fuzzy reference image of the vacancy $\mathrm{V}_{1}$ can be described as follows:

$$
\widetilde{V}_{1}=\left\{1 / l_{1} ; 1 / l_{2} ; 1 / l_{3} ; 1 / c_{1} ; 1 / c_{2} ; 1 / c_{3} ; 1 / c_{4} ; 1 / u_{1} ; 1 / u_{2} ; 1 / u_{3}\right\} \text {. }
$$

4th stage. Fuzzy similarity degree of the fuzzy real situations formed by the applicants to the reference situation is designated. For this purpose, using the formula (6), the equality degree of the fuzzy real and reference situations according to L, C, U. Based on the obtained results, the fuzzy similarity degree of the real situation to the reference situations, i.e., $\mu\left(\tilde{V}_{1}, \widetilde{S}_{g}\right), g=\overline{1,4}$ is defined as follows:

$$
\begin{gathered}
\mu\left(\tilde{V}_{1}, \tilde{S}_{1}\right)=\mu_{L}\left(\tilde{V}_{1}, \tilde{S}_{1}\right) \& \mu_{C}\left(\tilde{V}_{1}, \tilde{S}_{1}\right) \& \mu_{U}\left(\tilde{V}_{1}, \tilde{S}_{1}\right)=0,87 \& 0,82 \& 0,82=0,82, \\
\mu\left(\tilde{V}_{1}, \tilde{S}_{2}\right)=\mu_{L}\left(\tilde{V}_{1}, \tilde{S}_{2}\right) \& \mu_{C}\left(\tilde{V}_{1}, \tilde{S}_{2}\right) \& \mu_{U}\left(\tilde{V}_{1}, \tilde{S}_{2}\right)=0,8 \& 0,4 \& 0,82=0,8, \\
\mu\left(\tilde{V}_{1}, \tilde{S}_{3}\right)=\mu_{L}\left(\tilde{V}_{1}, \tilde{S}_{3}\right) \& \mu_{C}\left(\tilde{V}_{1}, \tilde{S}_{3}\right) \& \mu_{U}\left(\tilde{V}_{1}, \tilde{S}_{3}\right)=0,7 \& 0,75 \& 0,8=0,7, \\
\mu\left(\tilde{V}_{1}, \tilde{S}_{4}\right)=\mu_{L}\left(\tilde{V}_{1}, \tilde{S}_{4}\right) \& \mu_{C}\left(\tilde{V}_{1}, \tilde{S}_{4}\right) \& \mu_{U}\left(\tilde{V}_{1}, \tilde{S}_{4}\right)=0,65 \& 0,7 \& 0,88=0,65 .
\end{gathered}
$$

5th stage. The results of the expert assessments of the compliance of the applicants with the indicators characterizing the vacancy $\mathrm{V}_{2}$ are given in Table 5.

Table 5 .

Linguistic values of the compliance of the applicants with the indicators characterizing the

\begin{tabular}{|l|c|c|c|c|}
\hline \multicolumn{1}{|c|}{ Applicants to the vacancy $V_{2}$} & $S_{1}$ & $S_{2}$ & $S_{3}$ & $S_{4}$ \\
\hline $\begin{array}{l}\text { Indicators } \\
\text { characterizing the vacancy } V_{2}\end{array}$ & & & & \\
\hline Personal qualities $(\boldsymbol{L})$ & good & Good & good & Good \\
\hline sociable, friendly $\left(l_{1}\right)$ & normal & Good & Normal & good \\
\hline adaptable $\left(l_{2}\right)$ & & & & \\
\hline Competence, knowledge and skills $(\boldsymbol{C})$ & excellent & excellent & good & excellent \\
\hline $\begin{array}{l}\text { level of knowledge in accordance with the } \\
\text { university diploma in "pediatrics" }\left(c_{1}\right)\end{array}$ & excellent & excellent & good & Good \\
\hline perfect knowledge of vocational skills $\left(c_{2}\right)$ & & & & Good \\
\hline Terms and requirements $(\boldsymbol{U})$ & Good & Good & Normal & Good \\
\hline living and working in villages and districts $\left(u_{1}\right)$ & normal & Good & Normal & Good \\
\hline intense work scheduleif necessary $\left(u_{2}\right)$ & excellent & excellent & good & Good \\
\hline Fluent Azerbaijani $\left(u_{3}\right)$ & & & & \\
\hline
\end{tabular}

Based on Table 5, fuzzy real images of the applicants to the vacancy $V_{2}$ are formed.

$$
\begin{aligned}
& \tilde{S}_{1}=\left\{0,85 / l_{1} ; 0,6 / l_{2} ; 0,97 / c_{1} ; 0,98 / c_{2} ; 0,8 / u_{1} ; 0,65 / u_{2} ; 0,96 / u_{3}\right\} \\
& \tilde{S}_{2}=\left\{0,9 / l_{1} ; 0,92 / l_{2} ; 0,96 / c_{1} ; 0,96 / c_{2} ; 0,9 / u_{1} ; 0,9 / u_{2} ; 0,96 / u_{3}\right\} \\
& \tilde{S}_{3}=\left\{0,88 / l_{1} ; 0,75 / l_{2} ; 0,85 / c_{1} ; 0,82 / c_{2} ; 0,75 / u_{1} ; 0,77 / u_{2} ; 0,85 / u_{3}\right\} \\
& \tilde{S}_{4}=\left\{0,86 / l_{1} ; 0,94 / l_{2} ; 0,96 / c_{1} ; 0,85 / c_{2} ; 0,88 / u_{1} ; 0,85 / u_{2} ; 0,9 / u_{3}\right\}
\end{aligned}
$$

Fuzzy reference images of the vacancy $V_{2}$ can be described as:

$$
\widetilde{V}_{2}=\left\{1 / l_{1} ; 1 / l_{2} ; 1 / c_{1} ; 1 / c_{2} ; 1 / u_{1} ; 1 / u_{2} ; 1 / u_{3}\right\}
$$


Based on the formula (6), fuzzy equality degrees of the fuzzy real and reference situations are calculated according to $\mathrm{L}, \mathrm{C}, \mathrm{U}$, and fuzzy similarity degrees $\mu\left(\tilde{V}_{2}, \tilde{S}_{g}\right), g=\overline{1,4}$ of these situations are defined on the basis of following formulas:

$$
\begin{gathered}
\mu\left(\tilde{V}_{2}, \tilde{S}_{1}\right)=\mu_{L}\left(\tilde{V}_{2}, \tilde{S}_{1}\right) \& \mu_{C}\left(\tilde{V}_{2}, \tilde{S}_{1}\right) \& \mu_{U}\left(\tilde{V}_{2}, \tilde{S}_{1}\right)=0,6 \& 0,97 \& 0,65=0,6 ; \\
\mu\left(\tilde{V}_{2}, \tilde{S}_{2}\right)=\mu_{L}\left(\tilde{V}_{2}, \tilde{S}_{2}\right) \& \mu_{C}\left(\tilde{V}_{2}, \tilde{S}_{2}\right) \& \mu_{U}\left(\tilde{V}_{2}, \tilde{S}_{2}\right)=0,9 \& 0,96 \& 0,9=0,9 ; \\
\mu\left(\tilde{V}_{2}, \vec{S}_{3}\right)=\mu_{L}\left(\tilde{V}_{2}, \tilde{S}_{3}\right) \& \mu_{C}\left(\tilde{V}_{2}, \tilde{S}_{3}\right) \& \mu_{U}\left(\tilde{V}_{2}, \tilde{S}_{3}\right)=0,75 \& 0,82 \& 0,75=0,75 ; \\
\mu\left(\tilde{V}_{2}, \tilde{S}_{4}\right)=\mu_{L}\left(\tilde{V}_{2}, \tilde{S}_{4}\right) \& \mu_{C}\left(\tilde{V}_{2}, \tilde{S}_{4}\right) \& \mu_{U}\left(\tilde{V}_{2}, \tilde{S}_{4}\right)=0,86 \& 0,85 \& 0,88=0,85 .
\end{gathered}
$$

The obtained results are provided in Table 6.

Table 6.

Fuzzy similarity degrees $\mu\left(\tilde{V}_{1}, \tilde{S}_{g}\right), g=\overline{1,4}$ and $\mu\left(\tilde{V}_{2}, \tilde{S}_{g}\right), g=\overline{1,4}$

\begin{tabular}{|c|c|c|}
\hline Applicants & $\mu\left(\tilde{V}_{1}, \widetilde{S}_{g}\right), g=\overline{1, q}$ & $\mu\left(\tilde{V}_{2}, \widetilde{S}_{g}\right), g=\overline{1, q}$ \\
\hline$S_{1}$ & $\mathbf{0 , 8 2}$ & 0,6 \\
\hline$S_{2}$ & 0,8 & $\mathbf{0 , 9}$ \\
\hline$S_{3}$ & 0,7 & 0,75 \\
\hline$S_{4}$ & 0,65 & 0,85 \\
\hline
\end{tabular}

6th stage. Pending case scenario corresponds to 2.1, i.e.,fuzzy reference situation $\mathrm{V}_{1}$ and real situations $\tilde{S}_{1}, \tilde{S}_{2}, \tilde{S}_{3}$ are fuzzy similar and real situations and the closest one to the real image is the real situation $S_{1}\left(\mu\left(V_{1}, S_{1}\right)=0.82\right)$.Fuzzy reference situation $\mathrm{V}_{1}$ and fuzzy real situation $S_{4}$ arenot fuzzy equal, and the equality degree of this "pair" is less than the fuzzy equality limit, that is $\mu\left(V_{1}, S_{4}\right)=0,65<0,7$.

Fuzzy reference situation $\mathrm{V}_{2}$ and real situations $\tilde{S}_{2}, \tilde{S}_{3}, \tilde{S}_{4}$ are fuzzy similar, and the closest one to the real image is the real situation $S_{2}\left(\mu\left(V_{2}, S_{2}\right)=0.9\right)$. The pair of the images $V_{2}$ and $S_{1}$ are not fuzzy equal, that is $\mu\left(V_{2}, S_{1}\right)=0,6<0,7$.

7th stage. Assuming an employer is interested in taking into account the relative superiority of the indicators in selecting the most appropriate applicants. In this case, the decision is made in accordance with the scenario 2.2 (real situations $S_{4}$ and $S_{1}$ for the vacancies $V_{l}$ and $V_{2}$, respectively, are not considered at this stage).

Relative importance ratios are determined by referring to Table 1based on the following expert assessment about the relative superiority of the criteria $\mathrm{L}, \mathrm{C}$ and $\mathrm{U}$ characterizing the vacancy $V_{l}$ andthe relative superiority of the certain indicators characterizing them:

- "competence, knowledge and skills (C) are much more important compared to personal qualities (L), and less important compared to terms and requirements (U)";

- "responsible (L2) is considerably much more important compared to sociable and friendly (L1), self-developing (L3)";

- "level of knowledge in accordance with the university diploma $\left(c_{1}\right)$ and perfect knowledge of vocational skills $\left(c_{2}\right)$ are noticeably much more important compared to assured computer skills $\left(c_{2}\right)$ and presentation of competent writing skills $\left(c_{4}\right) "$

- "minimum 3 years practical experience $\left(u_{1}\right)$ is significantly more important compared to re-qualification certificate $\left(u_{2}\right)$ and Fluent Azerbaijani and Russian language skills $\left(u_{3}\right)$ ".

Referring to the formulas (7) - (8), no contradiction is identified in the expert statements. The obtained results are given in Table 7 . 
Table 7.

\begin{tabular}{|c|c|c|c|c|c|c|}
\hline $\begin{array}{c}\text { Crite- } \\
\text { ria }\end{array}$ & $\begin{array}{l}\text { Criterion } \\
\text { impor- } \\
\text { tance } \\
\text { ratios }\end{array}$ & $\begin{array}{l}\text { Indi- } \\
\text { cators }\end{array}$ & $\begin{array}{l}\text { Indicators } \\
\text { importance } \\
\text { ratios }\end{array}$ & \begin{tabular}{|c|}
$S_{1}$ \\
$\mu_{L_{j}}\left(S_{1}\right) \rightarrow[0,1], j=\overline{1,4}$ \\
$\mu_{C_{f}}\left(S_{1}\right) \rightarrow[0,1], f=\overline{1,3}$ \\
$\mu_{U_{\gamma}}\left(S_{1}\right) \rightarrow[0,1], \gamma=\overline{1,3}$
\end{tabular} & $\begin{array}{c}S_{2} \\
\mu_{L_{j}}\left(S_{2}\right) \rightarrow[0,1], j=\overline{1,4}, \\
\mu_{C_{f}}\left(S_{2}\right) \rightarrow[0,1], f=\overline{1,3}, \\
\mu_{U_{\gamma}}\left(S_{2}\right) \rightarrow[0,1], \gamma=\overline{1,3}\end{array}$ & $\begin{array}{c}S_{3} \\
\mu_{L_{j}}\left(S_{3}\right) \rightarrow[0,1], j=\overline{1,4} \\
\mu_{C_{f}}\left(S_{3}\right) \rightarrow[0,1], f=\overline{1,3} \\
\mu_{U_{\gamma}}\left(S_{3}\right) \rightarrow[0,1], \gamma=\overline{1,3}\end{array}$ \\
\hline \multirow{3}{*}{$\mathrm{L}$} & \multirow{3}{*}{0,077} & $l_{l}$ & 0,07 & 0,97 & 0,88 & 0,82 \\
\hline & & $l_{2}$ & 0,465 & 0,89 & 0,85 & 0,89 \\
\hline & & $l_{3}$ & 0,465 & 0,87 & 0,8 & 0,70 \\
\hline \multirow{4}{*}{ C } & \multirow{4}{*}{0,693} & $c_{1}$ & 0,4166 & 0,98 & 0,95 & 0,82 \\
\hline & & $c_{2}$ & 0,4166 & 0,9 & 0,84 & 0,75 \\
\hline & & $c_{3}$ & 0,0834 & 0,95 & 0,97 & 0,80 \\
\hline & & $c_{4}$ & 0,0834 & 0,82 & 0,95 & 0,9 \\
\hline \multirow{3}{*}{$\mathrm{U}$} & \multirow{3}{*}{0,23} & $u_{1}$ & 0,714 & 0,90 & 0,94 & 0,97 \\
\hline & & $u_{2}$ & 0,143 & 0,82 & 0,82 & 0,97 \\
\hline & & $u_{3}$ & 0,143 & 0,95 & 0,95 & 0,8 \\
\hline
\end{tabular}

8th stage. Based on the formulas (10) - (12) the degree of similarity of the real images $S_{1}$, $S_{2}, S_{3}$ and the reference image $V_{1}$ by L, C, U is determined:

$\mu_{L}\left(\tilde{S}_{g}\right)=\sum_{j=1}^{3} \mu_{l j}\left(S_{g}\right) \cdot w_{l_{j}}, \quad \mu_{C}\left(\tilde{S}_{g}\right)=\sum_{f=1}^{4} \mu_{c_{f}}\left(S_{g}\right) \cdot w_{c_{f}}, \quad \mu_{U}\left(\tilde{S}_{g}\right)=\sum_{\gamma=1}^{3} \mu_{u_{\gamma}}\left(S_{g}\right) \cdot w_{u_{\gamma}}$.

The results are given in Table 8 .

Table 8.

Similarity degree of the real images by L, C, U

\begin{tabular}{|c|c|c|c|c|c|}
\hline \multirow{6}{*}{ Criteria } & $\begin{array}{c}\text { Criterion importance } \\
\text { ratios }\end{array}$ & $\begin{array}{c}\tilde{S}_{1} \\
\mu_{L}\left(S_{1}\right) \rightarrow[0,1] \\
\mu_{C}\left(S_{1}\right) \rightarrow[0,1] \\
\mu_{U}\left(S_{1}\right) \rightarrow[0,1]\end{array}$ & $\begin{array}{c}\tilde{S}_{2} \\
\mu_{L}\left(S_{2}\right) \rightarrow[0,1] \\
\mu_{C}\left(S_{2}\right) \rightarrow[0,1] \\
\mu_{U}\left(S_{2}\right) \rightarrow[0,1]\end{array}$ & $\begin{array}{c}\tilde{S}_{3} \\
\mu_{L}\left(S_{3}\right) \rightarrow[0,1] \\
\mu_{C}\left(S_{3}\right) \rightarrow[0,1] \\
\mu_{U}\left(S_{3}\right) \rightarrow[0,1]\end{array}$ \\
\hline \multirow{3}{*}{$V_{1}$} & $L$ & 0,077 & 0,88 & 0,83 & 0,8 \\
\cline { 2 - 6 } & $C$ & 0,693 & 0,93 & 0,91 & 0,8 \\
\cline { 2 - 6 } & $U$ & 0,23 & 0,9 & 0,92 & 0,95 \\
\hline
\end{tabular}

9th stage. Based on the formula (13) the degree of similarity of the applicants to the vacancy $V_{l}$ is determined:

$$
\mu\left(V_{1}, S_{i}\right)=\mu_{L}\left(S_{i}\right) \cdot w_{L}+\mu_{C}\left(S_{i}\right) \cdot w_{C}+\mu_{U}\left(S_{i}\right) \cdot w_{U} .
$$

The results are given in Table 9.

Table 9.

\begin{tabular}{|c|c|c|c|}
\hline & $\tilde{S}_{1}$ & $\tilde{S}_{2}$ & $\tilde{S}_{3}$ \\
& $\mu\left(V_{1}, S_{1}\right) \rightarrow[0,1]$ & $\mu\left(V_{1}, S_{2}\right) \rightarrow[0,1]$ & $\mu\left(V_{1}, S_{3}\right) \rightarrow[0,1]$ \\
\hline$\mu\left(\tilde{V}_{1}, \tilde{S}_{g}\right)$ & 0,919 & 0,906 & 0,834 \\
\hline
\end{tabular}

Thus, taking into account the importance ratios of the indicators, the real image of the applicant $S_{l}$ to the vacancy $V_{l}$ has the highest similarity degree to the reference image of the vacancy, and can be considered as the best decision. 
Similarly, taking into account importance ratios of indicators, the best applicant for the vacancy $V_{2}$ is identified.

\section{Conclusion}

The proposed method is one of the support options for employers to make more justified decisions in the recruitment to the vacancies by complying the demand and supply of health professionals. This issue can be solved by considering the mandatory, optional, insignificance of the qualifications characterizing the vacancy [21]; by reducing the issue to collective decision [22]; by reducing the decision-making process to the issue of multi-criterion decision-making considering the competence of the participants in the subject matter [23]. The importance of such support is conditioned by a number of factors, such as the dynamics of medical knowledge, the deepening of specialization, the unequal geographical and territorial distribution of health workforce, and therefore, the differing requirements for them, the high cost of training the qualified staff, increase in the value of healthcare workforces depending on their experience, increased demand for health specialists in exchange for the tendency to decrease the supply and so on. Under these conditions, the modern employer must adapt his/her decisions to the changing management situations. Additionally, today, the number of the decisions to be made in uncertainty and nonstandard situations, at all levels of management, has significantly increased. Since the human resources is the key determinant for the competitiveness of organization, it is strategically important to support the decision related to the staff and its intellectual potential.

\section{References}

1. "Development Program for the provision of medical personnel of the health care institutions in the Republic of Azerbaijan for 2010-2014" www.e-qanun.az/framework/20002

2. "Azerbaijan 2020: look into the future" concept of development www.president.az/files/future_az.pdf

3. Dussault G., Buchan J., Sermeus W., Padaiga Z. Assessing future health workforce needs, Policy summary prepared for the Belgian EU Presidency Conference on Investing in Europe's health workforce of tomorrow: scope for innovation and collaboration (La Hulpe, 9-10 September 2010. www.euro.who.int/_data/assets/pdf_file/0019/124417/e94295.pdf

4. Green paper. On the European workforce for health. Commission of the European communities. Brussels 10.12.2008. COM (2008) 725 final. EN). http://ec.europa.eu/health/ph_systems/docs/workforce_gp_en.pdf

5. Mammadova M.H., Jabrayilova Z.G. Modeling of the interaction between supply and demand for medical staff on the basis of fuzzy situational analysis // Problems of information technology, 2017, no.1, pp.26-35.

6. Mammadova M.H., Jabrayilova Z.G. About one approach to intelligent managing of health specialists labor market / Proceedings of International Conference of Advances Technology and Science, 2-4 September, Konya, pp.1408-1412.

7. L.A.Zadeh, The concept of a linguistic variable and its application to the adoption of approximate solutions, M .: Mir, 1976, $168 \mathrm{p}$.

8. Mammadova M.H. Decision-making based on knowledge bases with a fuzzy relational structure, Baku: ELM, 1997, p.296.

9. Melikhov A.N., Bernshtein L.S., Korovin S.Ya. Situational advisory systems with fuzzy logic, M.: Nauka, 1990, p.272.

10. Mammadova M.H., Jabrayilova Z.G. Qualitative analysis and assessment of piloting techniques based on flight information. Overview information. Series: "Automation and telemechanics. Computing Machinery", AzNIINTI, Baku, 1998, 74 p.

11. Mammadova M.H., Jabrayilova Z.G. Multi-criteria model of decision-making support in the personnel management problems // Problems of information technology, 2012, no.2, pp.37-46. 
12. Saaty T.L. Decision-making. The method of analyzing hierarchies, M.: Radio and communication, 1993, p.320.

13. Djabrailova Z.G., Nobari S.M. Defining methods of importance factor of the criteria in the solution of personnel management problems and detection of contradictions / PRIP'2011 Pattern Recognition and Information processing / 18-20 may 2011, Minsk, Belarus, pp.330-333.

14. Neyman D., Morgenstern O. Game theory and economic behavior. M .: Nauka, 1970, p.708.

15. https://jobs.day.az

16. www.olx.kz/rabota/meditsina-farmatsiya/astana/

17. http://e-health.gov.az/vakansiyalar/Vezife_telimat_pdf/MR_V5A_son-MoH.pdf

18. www.rabota.az/vacancy/sehiyye-eczailiq/tibbi-personal

19. Larichev O.I. Verbal analysis of decisions. M .: Science, 2006, 181 p.

20. Bellman R., Zadeh L.A. Decision-making in fuzzy environment // Management Science, 1970, vol.17, pp.141-164.

21. Mamedova M.G., Jabrailova Z.Q., Mammadzada F.R. Fuzzy Multi-scenario Approach to Decision-Making Support in Human Resource Management. In book: L.A.Zadeh et al. (eds.), Recent Developments and New Direction in Soft-Computing Foundations and Applications, Studies in Fuzziness and Soft Computing, Springer International Publishing Switzerland 2016, vol.342, pp.19-36. DOI 10.1007/978-3-319-32229-2_3

22. Mammadova M.G., Jabrayilova Z.G. Application of TOPSIS Method in Support of Decisions Made in Staff Management Issues // Computer Technology and Application, 2013, vol.4, no.6, pp.307-316.

23. Mammadova M.H., Jabrayilova Z.G. Methodological approach to multi-criteria decisionmaking in the personnel management problems // Problems of information technology, 2012, no.2, pp.467-480. 